\title{
Ağaç Ürünleri Üreten Bir İşletmede Malzeme Taşıma Sisteminin Simülasyon Yaklaşımıyla İyileştirilmesi
}

\author{
Yusuf KUVVETLI $^{* 1}$, Rizvan EROL $^{1}$ \\ ${ }^{1}$ Çukurova Üniversitesi, Mühendislik Mimarllk Fakültesi, Endüstri Mühendisliği Bölümü, Adana
}

Geliş tarihi: 27.01.2017～Kabul tarihi: 14.03.2017

\section{Öz}

Üretim içi malzeme taşıma sistemleri, üretimin hem iş sağlığı ve güvenliğine uygun yürütülmesi hem de sürekliliğinin sağlanması açısından kritik öneme sahiptir. Özellikle yüksek hacim ve ağırlıktaki nesnelerin iş merkezleri arasında transferi oldukça sorunludur. Bu çalışmada, ağaç ürünleri üretimi yapan bir işletmede üretim sahasındaki iş merkezleri arasındaki malzeme taşıma sistemi ele alınmış ve taşıma alternatifleri kesikli olay simülasyonu yaklaşımıyla değerlendirilmiştir. Sonuçlara göre, konveyör sistemlerinin kullanımının istatistiksel olarak anlamlı olduğu görülmüştür. Yatırım kararları göz önüne alındığında da konveyör sistemlerinin kullanımının uzun dönemde daha uygun olduğu görülmüştür.

Anahtar Kelimeler: Malzeme taşıma sistemleri, Sistem simülasyonu, İç lojistik, Taşıma alternatifleri

\section{Improving Materials Handling Systems via Simulation Approach for a Woodworking Manufacture Company}

\begin{abstract}
Ensuring both of the production sustainability and working with suitable conditions to occupational health and safety makes in-bound material handling systems critically important. Especially, transferring objects having high volume and weight between work centers causes a lot of problems. In this study, the material handling system between the work centers on a production site for a woodworking manufacturer is considered and the transportation alternatives are evaluated via discrete event simulation approach. According to results, using conveyor systems is found statistically significant. When investment costs are considered, using conveyor systems are more suitable in long term.
\end{abstract}

Keywords: Materials handling systems, System simulation, Inbound Logistics, Handling alternatives

*Sorumlu yazar (Corresponding author): Yusuf KUVVETLİ, ykuvvetli@cu.edu.tr 


\section{GíRiș}

Malzeme taşıma sistemleri ve lojistik; üretim, dağıtım, tüketim ve imha etme süreci boyunca malzemelerin ve ürünlerin hareketi, saklanması, korunması ve kontrolünü ifade eder [1].

İyi bir malzeme taşıma sistemi için gereklilikler şunlardır [2]:

- Malzemelerin istenilen yere etkin ve güvenli hareketi,

- Malzemeye ihtiyaç duyulan zamanda aktarımı,

- İstenilen miktarda malzeme sağlanması,

- Minimum alan kullanımı ile malzemelerin saklanması

- Ve bu aktivitelerin minimum maliyet ile gerçekleştirilmesidir.

Malzeme taşıma sektörü birliği (MHI) tarafindan yayınlanan 2016 yılı sektör raporuna göre, malzeme taşıma sistemlerinde yeni kullanılan teknolojiler olarak robotik ve otomasyon, envanter ve ağ optimizasyon araçları ve sensorlar ve otomatik tanımlama sistemleri görülmektedir. Aynı zamanda bu sistemlerin en büyük uygulama zorluğunu ise kurulum ve bakım maliyetleri oluşturmaktadır [3].

Malzeme taşıma sistemleri bu nedenlerle bir üretim sisteminin düzenli işleyebilmesi için kritik bir öneme sahiptir. Malzeme taşıma sistemlerinin seçim kararları işletmeler için önem taşımaktadır. $\mathrm{Bu}$ çalışmada, ağaç işleri üretimi yapan bir işletmenin malzeme taşıma sisteminin kesikli olay simülasyonu yaklaşımıyla iyileştirilmesi amaçlanmıştır.

Kesikli olay simülasyonu yaklaşımı, durum değişkenlerinin zamanın ayrık noktalarındaki değişiminin gösterildiği bir sistemin zaman üzerindeki değişimidir [4]. Başka bir deyişle, incelenen sistemin zaman içerisindeki belirli noktalar (olaylar) arasındaki değişimiyle hesaplama yapılmasidır.

Simülasyon yaklaşımının kullanımı aşağıdaki durumlarda uygundur [5]:
- Kompleks bir sistemin ilişkilerini göstermek ya da bir alt sisteme de uyarlamak,

- Farklı koşullarda sistemin nasıl etkileneceğini incelemek,

- Modelleme sirasindaki analizler ile sistemin iyileştirilmesini sağlamak,

- Yürüyen sistemin durdurulmasından kaynaklı zaman ve para kaybı oluşmadan öğrenmek,

- Analitik çözümlerin doğrulanmasını sağlamak.

Tüm bu sebeplerden dolayı, simülasyon yaklaşımı artan teknoloji ile birlikte test edilmesi güç olan alternatif senaryoların bilgisayar ortamında modellenmesine olanak tanır. Böylelikle karar vericiler, bilgisayar ortamında modellenen (benzetilen) sistem ile yatırım yapma veya yatırımdan vazgeçme gibi kararları verebilir.

\section{2. ÖNCEKİ ÇALIŞMALAR}

Literatürde, malzeme taşıma sistemlerinde simülasyon yaklaşımıyla karar verilmesi üzerine çalışmalar yapılmıştır. Bu amaçla, yapılan ilk çalışmalarda hangi metodolojilerin kullanılabileceği, bilgisayar simülasyonu uygulamaları gibi konular ele alınmıştır [6-10]. Bilgisayar uygulamalarının yanı sira farklı simülasyon dilleri için malzeme taşıma elemanlarının simülasyonu ele alınmıştır [11].

Bir diğer konu ise malzeme taşıma sistemi tasarımının uygulama aşamalarıdır. $\mathrm{Bu}$ amaçla, malzeme taşıma sistemi tasarımındaki dört aşama olan kavramsal, detaylı tasarım, kurulum ve uygulama aşamalarında simülasyonun kullanımı incelenmiştir [12].

Farklı uygulama alanlarına bakıldığında inşaat sektöründe [13,14], esnek üretim sistemlerinde [15], yarı iletken üretiminde [16-18], madenlerdeki taşıma sistemlerinde [19-21] malzeme taşıma sistemlerinin tasarım aşamalarında simülasyon yaklaşımı kullanılmıştır. Bir diğer çalışmada, kanban türü taşıma yapılan montaj hatlarında simülasyon yardımıyla malzeme taşıma alternatifleri değerlendirilmiştir [22]. Otomatik yönlendirmeli araçların (AGV) olduğu bir üretim ortamının performans ölçümü için simülasyon ve 
deney tasarımı yaklaşımları birlikte kullanılmıştır [23].

Önceki çalışmalar incelendiğinde, malzeme taşımanın zor olduğu inşaat, maden gibi sektörlerde ve malzeme akışının hızlı ve esnek olduğu üretim sistemlerinde (yarı iletken üretimi gibi) malzeme taşıma kararları için simülasyon yaklaşımı etkin olarak kullanılmıştır. Bu çalışmada ise taşıma ve depolaması zor olan ağaç ürünleri üretimi yapan bir firmada malzeme taşıma alternatifleri simülasyon yaklaşımıyla değerlendirilmiştir.

\section{MATERYAL VE METOT}

\subsection{Materyal}

$\mathrm{Bu}$ çalışmanın materyalini ağaç işleri üretimi yapan bir firmadan alınan veriler oluşturmaktadır. İncelenen işletmedeki üretim ortamının malzeme akışı Şekil 1'de görülmektedir. Buna göre tomruk halinde gelen ağaçlar sisteme beslenmekte, kapak kesimi ve yan alma işlemleri uygulanan tahtalar gerekli olursa boy kesimi yapılarak ayırma alanında paketlenmektedir.

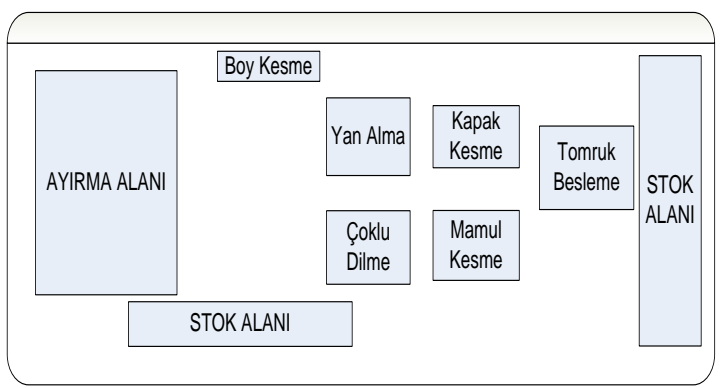

Şekil 1. İncelenen üretim sisteminin yerleşim planı

Sistemde üretilen ürün sayısı çok fazla olduğu için benzer ürünler gruplandırılmış ve en sık üretilen beş ürün grubu için planlama yapılmıştır. Buna göre boy kesme sürecine sadece 4 ve 5 numaralı ürünler girmektedir. Mevcut sistemde taşımalar vinç yardımıyla yapılmaktadır. 50 adet malzeme biriktiğinde vinçle istasyonlar arası aktarım gerçekleşmektedir. İstasyonlar arası mesafeler Çizelge 1'de görülmektedir. Yalnızca taşıma yapılan istasyonlar çizelgede yer almaktadır.
Çizelge 1. Kum için model parametreleri

\begin{tabular}{|c|c|c|}
\hline İstasyon & İstasyon & Mesafe \\
\hline Kapak Kesme & Yan Alma & $10 \mathrm{~m}$ \\
\hline Yan Alma & Boy Kesme & $10 \mathrm{~m}$ \\
\hline Yan Alma & Ayırma Alanı & $30 \mathrm{~m}$ \\
\hline Boy Kesme & Ayırma Alanı & $20 \mathrm{~m}$ \\
\hline
\end{tabular}

\subsection{Metot}

\subsubsection{Problemin Tanımı}

Ağaç ürünlerinin büyük hacim ve ağırlığa sahip olmasından dolayı işletme içinde taşıması ve depolanmasi sorunludur.

Ağaç ürünleri, canlı (yaş) ürün oldukları için ürünün güneşte ve nemli ortamlarda belirli bir süreden daha fazla depolanabilmelerinin zor olması stoklamayla ilgili en önemli sorundur.

Üretim içi stokların en önemli sebebi ise istasyonlar arası biriktirme ile malzemelerin aktarılmasıdır. Üretimdeki gereksiz beklemeler, bazı siparişler için stok olduğu halde yeniden üretilmesi ve sistemdeki malzeme miktarının fazlalığı sorununa neden olmaktadır.

Taşıma ve depolama probleminin çözümü için üretim içerisindeki malzeme akışlarının düzenli hale getirilmesi amacıyla farklı malzeme taşıma alternatifleri değerlendirilmiştir. Oluşturulan simülasyon modelinin akış şeması Şekil 2'de görülmektedir. Buna göre sisteme siparişler, bir teorik istatistiksel dağılıma göre rastgele gelmekte ve ardından sırasıyla üretim süreçlerini tamamlamaktadır. Her bir prosesin ardından belirlenen sayıda malzeme stokta oluştuğu zaman taşıma vinçleri yardımıyla aktarım yapılmaktadır.

\subsubsection{Veri Analizi}

Sistemin modellenmesinde ARENA Simülasyon yazılımı kullanılmıştır. Her bir proses ve gelişler arası sürelerin belirsiz olduğu kabul edilmiş ve 


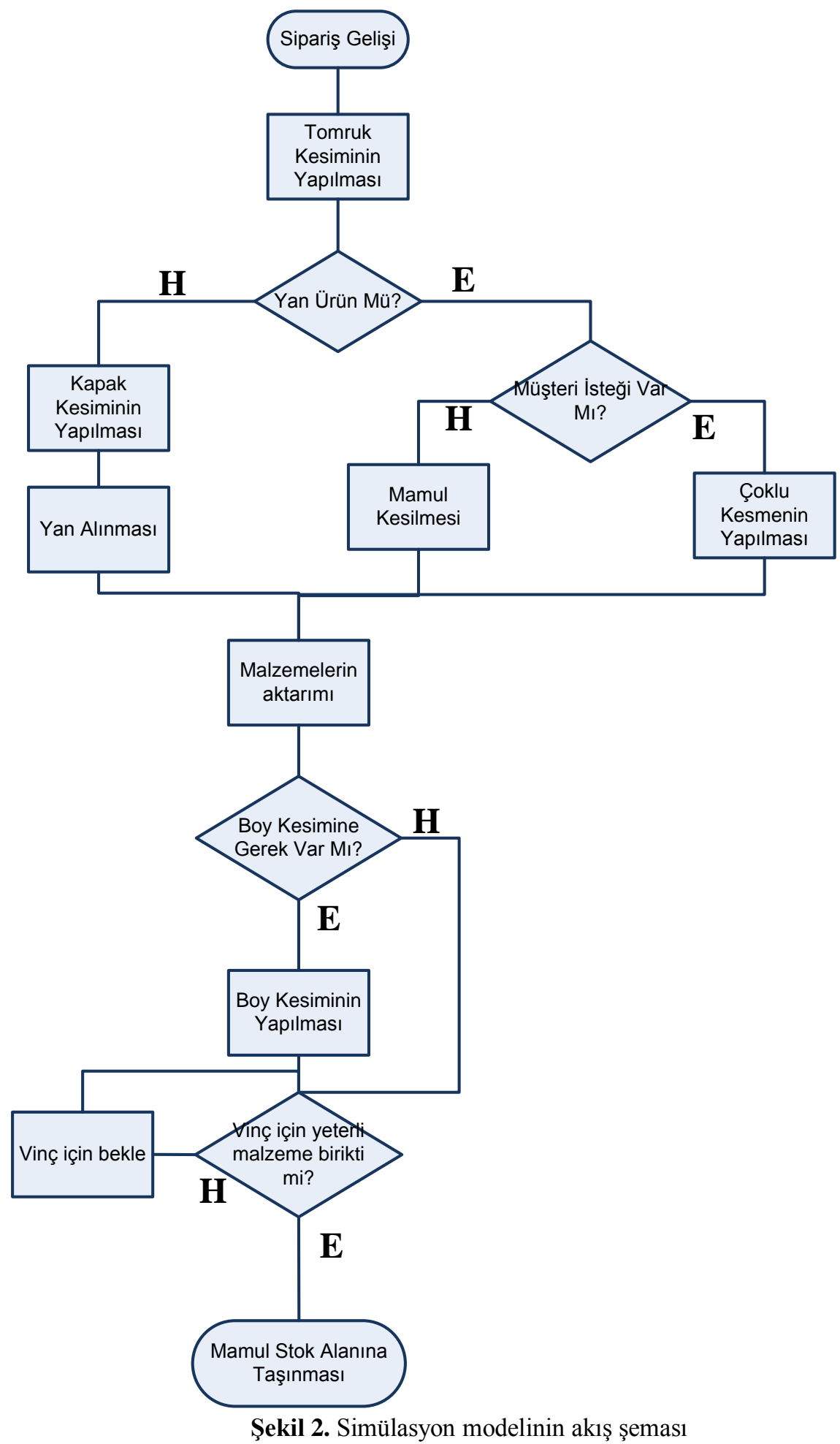


teorik istatistiksel dağılımlara uydurulmuștur. $\mathrm{Bu}$ amaçla Ki-kare test istatistiği hesaplanmış ve p değeri $\alpha$ düzeyinden $(0,05)$ yüksek olan teorik dağılımların verileri temsil edebileceği sonucuna ulaşılmıştır.

\subsection{3. Çıtı Analizi}

Simülasyon çalışmasının sonuçlarının anlamlı olabilmesi için çıktı analizi gerçekleştirilmiştir. Bu amaçla,

- Isinma periyodunun belirlenmesi,

- Replikasyon (koşum) sayısının belirlenmesi,

- Gerçek sistemle validasyonun yapılması,

- Alternatifler arasından en iyisinin seçilmesi için çıktı analizi yapılmıştır.

Bir simülasyon modeli, başlangıç anında hiçbir varlığın bulunmadığı (boş) koşullarda başlar. Başlangıç koşullarının sonuçları etkilememesi için sistemin belirli bir zaman boyunca çalıştırılarak sonuçlardan bu periyodun (1sınma periyodu) atılması gereklidir. Isınma periyodunun belirlenmesinde Welch yöntemi kullanılmıştır [4]. Grafiksel analiz yöntemi olan bu yöntemde, belirlenen bir w sayısı kadar kayan ortalama alınarak performans ölçütünün simülasyon uzunluğu boyunca grafiği çizilir. Ortalamaların düzgün bir doğrultuda ilerlemeye başladığı nokta ısınma periyodu olarak ele alınır. Bu çalışmada, performans ölçütü olarak ortalama sistemde kalma süresi alınmıştır.

Replikasyon sayısının belirlenmesinde bağıl hataya bağlı sabit örnek büyüklüğü yöntemi kullanılmıştır. $\mathrm{Bu}$ yöntemde ilk başta $\mathrm{n}$ replikasyon alınır. Sonrasında $\mathrm{n}$ replikasyon için ortalama ve varyans hesaplanır ve $i$ adet replikasyonun uygunluğu Eşitlik 1'deki gibi değerlendirilir [4].

$\overline{X(n)}=\mathrm{n}$ replikasyon ortalamas

$S^{2}=$ n replikasyon varyans 1

$t_{i, 1-\alpha / 2}=\mathrm{t}$ dağılım değeri(i serbestlik dereceli, alfa güven düzeyine sahip)

$\gamma=$ hata oranı

$\gamma^{I}=$ bağll hata $(\gamma /(1+\gamma))$ $n_{i}^{*}(\gamma)=\left\{i \geq n: \frac{t_{i-1,1-\alpha / 2} \sqrt{s^{2} / i}}{|\bar{X}(n)|}\right\} \leq \gamma^{I}$

Gerçek sistemle simülasyon sonuçlarının validasyonu için iki örneklemin aynı dağılımdan olup olmadığını ölçmek içinse Mann Whitney U testi kullanılmıştır.

\subsubsection{Alternatif Sistemlerin Modellenmesi}

Mevcut sistemde vinçlerle malzemelerin bekletilmesiyle taşımalar gerçekleştirilmektedir. $\mathrm{Bu}$ çalışmanın ana amacı incelenen üretim sistemindeki malzeme taşıma sisteminin iyileştirilmesidir. $\mathrm{Bu}$ amaçla, konveyör sistemi alternatif sistem olarak önerilmiştir. Mevcut durumda vinçlerle yapılan taşımaların konveyörle yapılacağı durumda taşıma sisteminin nasıl olacağı incelenmiştir.

Konveyör kullanımıyla ilgili olarak iki alternatif değerlendirilmiştir. Öneri 1 olarak yalnızca ayırma alanı öncesi konveyör kullanımı düşünülmüştür. Öneri 2 olarak ise tüm üretim ortamında konveyör kullanımı incelenmiştir. Alternatif simülasyon modellerinin karşılaştırılmasında ise çift- $t$ testi kullanılmıştır.

\section{BULGULAR VE TARTIŞMA}

\subsection{Veri Analizi Sonuçları}

Çizelge 2'de her bir belirsizlik kaynağına ait verilere uyan teorik istatistiksel dağılımlar ve parametreleri görülmektedir.

P değeri, istatistiksel bir hipotez testinin ret kararının verilmesi için kullanılan bir ölçüttür. Çizelge 2'deki veri analiz sonuçları incelendiğinde, gelişler arası sürenin normal dağılıma, kapak kesme işleminin log-normal dağılıma ve yan alma işleminin normal dağılıma uyduğu görülmektedir $(\mathrm{p}>0,05)$. Boy kesme işleminin yapısı gereği çok sık tekrarlanmayan bir iş olması sebebiyle uzman görüşüyle üçgen dağılıma uyduğu varsayılmıştır. 
Çizelge 2. Veri analizi sonuçları

\begin{tabular}{|c|c|c|c|c|}
\hline $\begin{array}{c}\text { Veri } \\
\text { Kaynağ } 1\end{array}$ & $\begin{array}{c}\text { Ortalama } \\
(\mathrm{sn})\end{array}$ & $\begin{array}{c}\text { Std. } \\
\text { Sapma }\end{array}$ & Dă̆ılım & P değeri \\
\hline $\begin{array}{c}\text { Gelişler } \\
\text { aras1 süre } \\
(\mathrm{sn})\end{array}$ & 90,5 & 5,4 & Norm $(90,5,5,40)$ & 0,38 \\
\hline $\begin{array}{c}\text { Kapak } \\
\text { Kesme } \\
(\mathrm{sn})\end{array}$ & 31,94 & 2,39 & $\operatorname{Logn}(31,94,2,39)$ & 0,14 \\
\hline $\begin{array}{c}\text { Yan } \\
\text { Alma (sn) }\end{array}$ & 23,80 & 2,6 & Norm $(23,8,2,6)$ & 0,23 \\
\hline $\begin{array}{c}\text { Boy } \\
\text { Kesme } \\
(\mathrm{sn})\end{array}$ & \multicolumn{5}{|c|}{$\operatorname{TRIA}(30,35,40)$} \\
\hline
\end{tabular}

\section{2. Çıktı Analizi Sonuçları}

Isınma periyodunun belirlenmesinde $\mathrm{w}=20$ için elde edilen sonuçlar Şekil 3 'te sunulmuştur. Isınma periyodu bulguları incelendiğinde sistemin çok hızlı toparlandığı ve 10 gün sonra verilerin daha düzenli hareket ettiği görülmektedir. Bu nedenle ısınma periyodu 10 gün olarak seçilmiştir.

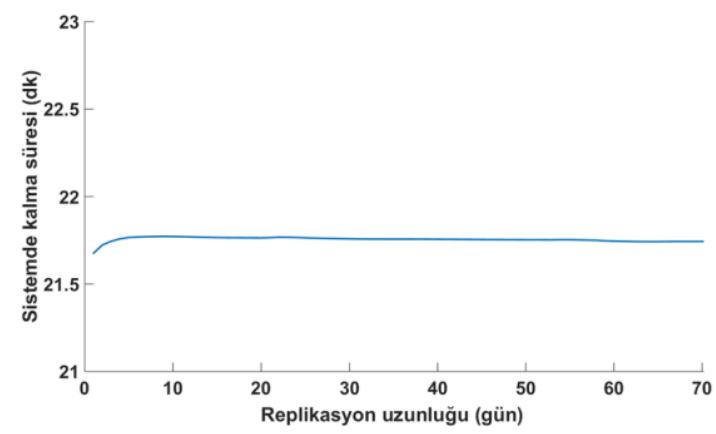

Şekil 3. Isınma periyodu sonuçları

Replikasyon sayısının belirlenmesi için ilk başta 10 replikasyon yapılmış ve 10 replikasyon ortalamas $21,75 \mathrm{dk}$ ve varyans $1,1 \mathrm{dk}$ olarak hesaplanmıştır. 30 replikasyon için ve $\gamma=0,1$ için (1) formülü hesaplandığında $0,01<0,09$ olduğundan 30 replikasyon yeterli görülmüsstür.

Simülasyon sonuçlarının gerçek sistemi yansıtıp yansıtmadığını ölçmek için validasyon yapılmıştır. $\mathrm{Bu}$ amaçla gerçek sistemden alınan gözlemlerle simülasyon sonuçları Mann Whitney U testi ile kıyaslanmış ve p değeri 0,5011 olarak hesaplanmıştır. Buna göre, gerçek sistemle simülasyon sonuçlarının aynı dağılımdan geldiği sonucuna ulaşılır ( $p>\alpha=0,05$ olduğundan). Bunun sonucu olarak önerilen simülasyon modelinin gerçek sistemi yansıttığı söylenebilir.

\subsection{Simülasyon Sonuçları}

Çıktı analizi sonucunda çalışma koşullarına karar verilen simülasyon modeli bir yıllık süre için çalıştırılmış ve sonuçlar elde edilmiştir. Buna göre sistemde kalma süresi ortalaması 21,77 dakika olarak gerçekleşmiştir.

Sistemdeki kuyruklar incelendiğinde en çok bekleme vincin gelişinde olmaktadır. Sistemde, ortalama olarak $18 \mathrm{dk}$ vincin aktarım yapması için beklemektedir. $\mathrm{Bu}$ durum sistemde kalma süresinin büyük çoğunluğunda vinç beklendiğini göstermektedir.

Kaynakların kullanım oranları incelendiğinde ise en çok kullanımın makinenin 0,53 ile yan alma makinesi olduğu görülmektedir. Sonrasında 0,34 ile boy kesme makinesi ve 0,1 ile kapak kesme makinesi gelmektedir.

Tüm bu veriler incelendiğinde mevcut durumdaki sistemde geçen sürenin büyük bir bölümünün taşımalar nedeniyle oluştuğu görülmektedir.

\subsection{Alternatiflerin Değerlendirilmesi}

Mevcut sistemle alternatif sistemlerin kıyaslanması için kullanılan çift t-testi sonuçları Çizelge 3'te görülmektedir. Buna göre, hesaplanan aralık sonuçlarının hiç biri 0 değerini içermemektedir. Aralıkların 0 değerini içermemesi karşılaştırılan sistemler arasındaki farklılığın istatistiksel olarak anlamlı olduğunu göstermektedir. Ortalamalar arası farklar incelendiğinde mevcut sistemin her iki sisteme göre oldukça farklı olduğu görülmektedir. Sistemde kalma süresinin en küçüklenmesi istendiğinden en kötü sistem mevcut sistem olmaktadır. Alternatifler incelendiğinde ise Öneri 2 alternatifinin ortalama $0.64 \mathrm{dk}$ daha kısa sürdüğü görülmektedir. $\mathrm{Bu}$ sonuçlar incelendiğinde en iyi sistemin tüm sistemde konveyör kullanımı (Öneri 2) olduğu görülmektedir. 
Çizelge 3. Kıyaslama sonuçları

\begin{tabular}{|c|c|c|c|c|}
\hline $\mathrm{i}-\mathrm{j}$ & $\bar{X}_{l}-\bar{X}_{J}$ & $\begin{array}{c}\text { Orta } \\
\text { Genişlik }\end{array}$ & \multicolumn{2}{|c|}{ Aralık } \\
\hline $\begin{array}{c}\text { Mevcut Sistem } \\
\text { - Öneri 1 }\end{array}$ & 18,0553 & 0,0188 & 18,0364 & 18,0741 \\
\hline $\begin{array}{c}\text { Mevcut Sistem } \\
\text { - Öneri 2 }\end{array}$ & 18,7031 & 0,0068 & 18,6963 & 18,7098 \\
\hline $\begin{array}{c}\text { Öneri 1- Öneri } \\
\text { 2 }\end{array}$ & 0,6478 & 0,0183 & 0,6295 & 0,6661 \\
\hline
\end{tabular}

Tüm sistemde konveyör kullanımı istatistiksel olarak anlamlı olsa da yatırım maliyetleri açısından anlamlı olmayabilir. Bu nedenle her iki alternatifin yatırım maliyetleri incelenmiş ve Şekil 4'te sunulmuştur. Her iki sistemin çalıştırılması için gerekli sabit (satın alma) ve değişken maliyetler (işletim ve işgücü) incelendiğinde 36 aydan uzun süreli bir yatırım düşünüldügüünde tüm sistemde konveyörlerin kullanımı (Öneri 2) mantıklı bir alternatif olarak ortaya çıkmaktadır.

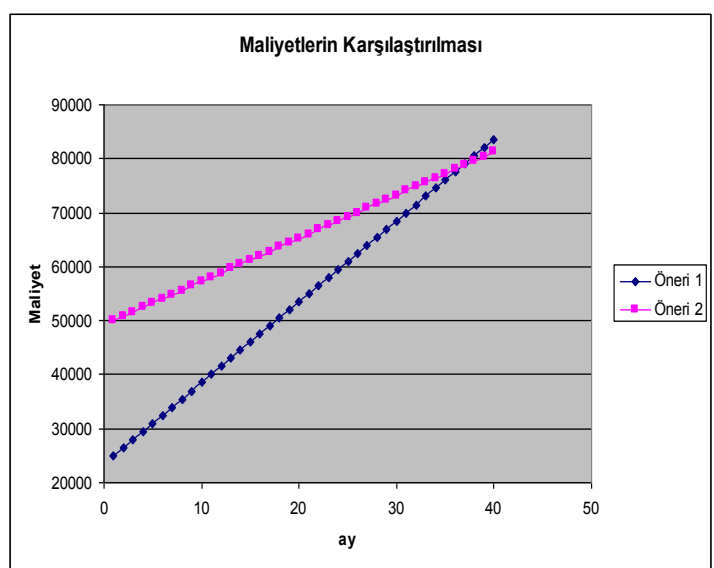

Şekil 4. Alternatif sistemlerin maliyetlerinin karşılaştırılması

\section{SONUÇ VE ÖNERILLER}

Malzeme taşıma sistemleri üretimin sürecinde kritik bir rol oynamaktadır. Bu çalışmada, malzeme taşıma sistemlerinin seçiminin üretimdeki beklemeler üzerine etkisi irdelenmiştir. $\mathrm{Bu}$ amaçla, ağaç işleri sektöründe faaliyet gösteren bir firmada alternatif taşıma sistemleri için simülasyon çalışması yapılmıştır.
Mevcut sistem için iki yeni alternatif sistem düşünülmüş ve modellenmiştir. Modelleme sonuçlarına göre her iki alternatifte mevcut duruma göre daha iyi sonuçlar vermiştir. Alternatifler arasında seçim yapabilmek için maliyetler incelenmiş ve buna göre 2. alternatifin (Öneri 2) seçilmesinin firma için uzun dönemde maliyet avantajı sağlayacağı görülmüştür.

Sonuç olarak büyük hacim ve ağırlıktaki ürünlerin bulunduğu bir sektör olan ağaç işleri sektöründe konveyör gibi taşıma alternatifinin üretimdeki beklemeleri azaltacağı ve sürekli akışı sağlayacağı görülmüştür.

Önerilen yaklaşımın benzer ürün tipleri üreten firmalarda da kullanılabilmesi ve farklı taşıma alternatiflerinin de değerlendirilmesi mümkündür.

\section{TEŞEKKÜR}

Bu çalışma, "Çukurova Üniversitesi Mühendislik Mimarlık Fakültesi 30. Y1l Bitirme Ödevi Proje Yarışması" kapsamında 1.lik ödülüne layık görülmüştür. Yazarlar tüm seçici jüriye teşekkür ederler.

\section{KAYNAKLAR}

1. Industry, M.H., 2016 27.12.2016]; Available from: http://www.mhi.org/about.

2. Ray, S., Introduction to Materials Handling. 2008: New Age International (P) Ltd. .

3. Industry, M.H., 2016. The 2016 MHI Annual Industry Report: Accelerating change: How innovation is driving digital, always-on supply chains.

4. Law, A.M., 2007. Simulation Modeling \& Analysis. Fourth Edition ed. New York: McGraw-Hill.

5. Banks, J., 2005. Discrete-Event System Simulation. Fourth Edition ed. Pearson/Prentice Hall.

6. Phillips, D.T., 1980. Simulation of Material Handling Systems-When and Which Methodology. Industrial Engineering, 12(9): p. 64-\&. 
7. Diaz, I., Lezman, S. 1988. Material Handling Simulation - Minimizing Bottlenecks and Improving Product Flow using Lotus 1-2-3. Industrial Engineering, 20(6): p. 40-46.

8. Foote Bobbie L., Ravindran, A., Adedeji, B., Badiru Lawrence M., Leemis Larry, Williams, M., 1988. Facilities and Material Handling Systems Series. 2. Simulation and Network Analysis Pay off in Conveyor System-Design. Industrial Engineering, 20(6), p. 48-53.

9. Lueck, G.A., 1988. Computer-Simulation of a Material-Handling and Storage-System. Tappi Journal, 71(7), p. 103-105.

10. Tabibzadeh, K., 1989. Simulation System for Material Handling-System Design. Computers \& Industrial Engineering, 17, p. 270-273.

11. Banks, J., 1990. The Simulation of Material Handling Systems. Simulation, 55(5), p. 261-270.

12. Ülgen, O.M., Upendram, S.S., 1995. The Role of Simulation Design of Material Handling Systems.

13. Wijesundera, D.A., Olomolaiye, P.O., Harris, F.C., 1991. Dynamic Simulation Applied to Materials Handling in High-Rise Construction. Computers \& Structures, 41(6): p. 1133-1139.

14. Chan, W.H., Lu, M., 2008. Materials Handling System Simulation 'n Precast Viaduct Construction: Modeling, Analysis, and Implementation. Journal of Construction Engineering and Management, 134(4): p. 300-310.

15. Devise, O., Pierreval, H., 1994. Simulation of the Motion of a Material Handling Mobile Robot in a Flexible Manufacturing System. Ciss - First Joint Conference of International Simulation Societies Proceedings, ed. J. Halin, W. Karplus, and R. Rimane. 483-487.

16. Nadoli, G., Pillai, D., 1994. Simulation in Automated Material Handling Systems Design for Semiconductor Manufacturing. 1994 Winter Simulation Conference Proceedings, ed. J.D. Tew, et al. 892-899.

17. Pierce, N.G., Stafford, R., 1994. Modeling and Simulation of Material Handling for Semiconductor Wafer Fabrication. 1994 Winter Simulation Conference Proceedings, ed. J.D. Tew, et al. 900-906.
18. Murray, S., Gerald, T., Mackulak, John W., Fowler, Theron C., Business, W.P., 2000. A Simulation-Based Cost Modeling Methodology for Evaluation of Interbay Material Handling in a Semiconductor Wafer Fab. Proceedings of the 2000 Winter Simulation Conference, Vols 1 and 2, ed. J.A. Joines, et al. 1510-1517.

19. Lebedev, A.A., Staples, P. 1998. Simulation of Materials Handling Systems in the Mines: Two Case Studies. Simulation, 70(3): p. 183-196.

20. Meng, C., Nageshwaraniyer S.S., Maghsoudi, A., Jun Son, Y., Dessureault, S., 2013. Datadriven Modeling and Simulation Framework for Material Handling Systems in Coal Mines. Computers \& Industrial Engineering, 64(3): p. 766-779.

21. Nageshwaraniyer, S.S., Son, Y.J., 2013. Dessureault, S. Simulation-based Optimal Planning for Material Handling Networks in Mining. Simulation-Transactions of the Society for Modeling and Simulation International, 89(3): p. 330-345.

22. Hao, Q., Shen, W.M., 2008. Implementing a Hybrid Simulation Model for a Kanban-based Material Handling System. Robotics and Computer-Integrated Manufacturing, 24(5): p. 635-646.

23. Subulan, K., Cakmakci, M., 2012. A Feasibility Study using Simulation-based Optimization and Taguchi Experimental Design Method for Material Handling-transfer System in the Automobile İndustry. International Journal of Advanced Manufacturing Technology, 59(5-8): p. 433-443. 